\title{
Editor's Briefing
}

\section{HIGHLIGHTS}

Diversity, opportunity, and flexibility are some of the most appealing features of general practice. A research career may not seem attractive initially but we might change our mind. If a bright enthusiastic doctor stumbles across a research idea, would like to become more involved, or decides to change course, the path can be difficult. Polly Duncan et al propose a collaborative framework that may help but we need to recognise that resources, time, funding, and publication opportunities are also limited.

In cancer treatment we focus on earlier identification of key clinical or biological markers in diagnosis. While science takes precedence, clinicians may be influenced by a vaguely defined gut feeling. Evidence and instinct collide in the systematic review by Claire Friedemann Smith et al, where gut feelings became more predictive as clinical experience and familiarity with the patient increased.

But, there is no mistaking the gut feeling in lona Heath's editorial. As she says in the accompanying video on BJGPLife.com nothing is more important than love'.

DOI: https://doi.org/10.3399/bjgp20X712157

\section{RESEARCH RESPONSIBLITIES}

Blood, sweat, and tears lie hidden behind every research paper. Reduced to a short abstract in the paper journal, and even with more generous online content, a manuscript only tells part of the whole story. It's a long journey from that first idea to final submission. The entire process is based on the commitment and generosity of others, and the advice and support of colleagues and mentors, not to mention the tolerance and forbearance of family and friends. But, most of all, the commitment and generosity of patients. The BJGPfamily has a responsibility to our research community and patients, to recognise this work, and to provide a platform for public-ation.

But, what should we publish in the BJGP? We would like you to help us decide - a form of shared decision making. Publishing on average eight research papers each month, we can only accept one or two articles, on average, each week. In recent weeks we have, for example, rejected beautifully written, methodologically excellent qualitative studies that didn't unfortunately offer any new insights; some excellent quantitative studies, using well validated databases and methodologically sound, but where there were no useful clinical outcomes; developmental work that will, undoubtedly, inform future work; excellent policy-related papers that reflected historical changes; systems/policy papers that reflected local change on the basis that $B J G P$ is an international journal and what we publish must be relevant to the primary care community throughout the UK and further afield and be equally meaningful in
Dulwich, Dundee, or Dunedin. We would like to move away from the traditional adversarial relationship between authors and the editor. Shared decision making also means shared responsibility. Together we need to decide, in general, what type of articles best represent the body of our academic work.

We also need to think progressively about our publication platforms. Grant giving bodies, national government, universities, and many publishers had already been looking at different public-ation models. The COVID-19 crisis has accelerated change in the dissemination of research using pre-prints, focused our attention on the importance of open data, catalysed the rapidity of publication, and altered how we think about sharing research findings. The landscape is changing with increasing use of university repositories and the availability of more sophisticated search tools. Journals were the first social network where authors could share and discuss their findings. Somewhere along the way we started putting up barriers to sharing research and creating narrow pipelines of information flow. The current archaic peer review to publication system is increasingly called into question. We can no longer cling to obsolete models and principles. The future will be about dissemination, curation, and interpretation. Research journals will need to adapt or slip quietly into obsolescence.

Domhnall MacAuley,

Editor, BJGP

DOI: https://doi.org/10.3399/bjgp20X712169

(c) British Journal of General Practice 2020; 698: 425-472
EDITOR

Domhnall MacAuley, MD, FRCGP, FFPHMI, FFSEM Belfast

DEPUTY EDITOR

Euan Lawson, FRCGP, FHEA, DCH

Lancaster

HEAD OF PUBLISHING

Catharine Hull

SENIOR ASSISTANT EDITOR

Amanda May-Jones

WEB EDITOR

Erika Niesner

ASSISTANT EDITOR

Moira Davies

ASSISTANT EDITOR

Tony Nixon

DIGITAL \& DESIGN EDITOR

Simone Jemmott

TRAINEE ASSISTANT EDITOR

Thomas Bransby

EDITORIAL ASSISTANT

Margaret Searle

EDITORIAL ADMINISTRATOR

Mona Lindsay

EDITORIAL BOARD

Luke Allen, MBChB, MPH, PGCE Clin Edu Oxford

Carolyn Chew-Graham, BSc, MD, FRCGP

Hajira Dambha-Miller, MSc, MPhil, MBBS Southampton

Graham Easton, MSc, MEd, SFHEA, FRCGP London

Adam Firth, MBChB, DTM\&H, DipPalMed

Stockport

Benedict Hayhoe, LLM, MD, MRCGP, DRCOG, DPMSA

London

Jennifer Johnston, PhD, MRCGP

Belfast

Brennan Kahan, BSc, MSc

London

Nada Khan, MSc, DPhil, MBBS

Leeds

Sarah Lay-Flurrie, BSc(Hons), MSc, DPhil

Sarah

David Misselbrook, MSc, MA, FRCGP

Bahrain

Peter Murchie, MSc, PhD, FRCGP

Aberdeen

Obioha Ukoumunne, BSc, MSc, PhD, FHEA

Exeter

Peter Schofield, BSc(Hons), MSc, PhD, PGCert

London

Liam Smeeth, MSc, PhD, FRCGP, FFPH

Liandon

\section{8 impact factor: 4.434}

EDITORIAL OFFICE

30 Euston Square, London, NW1 2FB.

Tel: 02031887400 , Fax: 02031887401

E-mail: journal(arcgp.org.uk / bjgp.org / बQB JGPjourna PUBLISHED BY

The Royal College of General Practitioners.

Registered charity number 223106 . The BJGP is published by the RCGP, but has complete editorial independence. by the RCGP, but has complete editorial independence. Opinions expressed in the BJGP should not be taken to
represent the policy of the RCGP unless this is specifically represent the policy of the RCGP unless this is specifically stated. No endorsement of
or intended by the RCGP. or intended by the RCG ISSN 1478-5242 (Online)

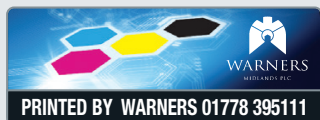

